\title{
Elaboração e implementação da produção técnica educacional: um guia prático e visual para "O ensino da matemática na educação infantil à partir da compreensão da cognição numérica"
}

Sidney Lopes Sanchez Júnior sid.educacaocp@gmail.com Universidade Federal do Paraná, Jandaia Universidade Federal

Marília Bazan Blanco mariliabazan@uenp.edu.br 0000-0001-9259-0578 Universidade Estadual do Norte do Paraná, Cornélio Procópio, Paraná, Brasil.

\section{RESUMO}

Os conhecimentos matemáticos estão presentes na vida da criança desde o seu nascimento, o que torna o envolvimento com números algo natural; no entanto, muitas crianças apresentam ansiedade à matemática e avaliações brasileiras têm demonstrado resultados não satisfatórios na aprendizagem desta disciplina. O Manual Ilustrado: "Um guia prático para o ensino de Matemática na Educação Infantil à partir da compreensão da Cognição Numérica" propõe caminhos que contribuem para o ensino da Matemática na Educação Infantil, visto a escassez de materiais produzidos nesta temática. Sendo assim, o objetivo geral deste artigo consiste na descrição da elaboração e implementação das atividades contidas na produção técnica supracitada, discutindo a aplicabilidade de suas atividades e analisando a percepção dos professores da educação Infantil quanto a sua contribuição para sua prática de ensino e seus conhecimentos em relação à Cognição Numérica. Os resultados da pesquisa revelam uma análise positiva do trabalho desenvolvido, aferindo que o Manual Ilustrado é aplicável na Educação Infantil e pertinente à realidade dos Centros Municipais de Educação Infantil, constituindo-se como um material facilitador e potencializador de aprendizagens, bem como na formação de professores. Ao professor que ensina Matemática na Educação Infantil, ressalta-se a importância da compreensão da Cognição Numérica para que tenham subsídios para sua prática e uma intervenção de qualidade.
\end{abstract}

PALAVRAS-CHAVE: Educação Infantil. Cognição Numérica. Ensino da Matemática. Formação de professores. 


\section{INTRODUÇÃO}

Desde o nascimento, as crianças já estão inseridas em um universo onde os conhecimentos matemáticos estão presentes (BRASIL, 1998), sendo o envolvimento com números algo natural. O contato com a Matemática fora da escola costuma ser prazeroso e as crianças se divertem com brincadeiras que envolvem números. No entanto, a aprendizagem da matemática na escola parece já não ser mais tão divertida (LORENA; CASTRO-CANEGUIM; CARMO, 2013), pois muitas crianças apresentam ansiedade à matemática (LORENA; CASTROCONEGUIM; CARMO, 2013, CARMO; SIMIONATO, 2012) e avaliações brasileiras têm demonstrado resultados não satisfatórios na aprendizagem dessa disciplina (PISA, 2016, BRASIL, 2016).

Constando tais dificuldades, surge a preocupação com o ensino da Matemática, e o Currículo Básico da Escola Pública do Estado do Paraná (PARANÁ, 2003) aponta que uma das causas do fracasso escolar é a escola não encontrar estratégias que vão ao encontro ou se relacionam com o dia a dia do aluno, distanciando o ensino das situações reais da vida da criança. $O$ documento salienta que a Matemática é a disciplina que mais reprova, cujo ensino ainda é marcado por uma Pedagogia Tradicional, e pouco mudou nas suas práticas, mesmo com novas propostas de ensino.

O trabalho com a Matemática na Educação Infantil visa auxiliar na formação de cidadãos autônomos, pensantes e capazes de resolver problemas, visto que as crianças já estão inseridas em um universo no qual os conhecimentos matemáticos fazem parte (BRASIL, 1998). Os Referenciais Curriculares para Educação Infantil RCNEI (BRASIL, 1998) são o documento federal que orienta a ação pedagógica do professor que atua na Educação Infantil, segundo o qual a criança constrói noções matemáticas por meio de interações com o meio e outras pessoas de forma intencional e planejada, em contato com histórias, músicas, contos, jogos e brincadeiras, de forma lúdica e prazerosa.

O documento supracitado subsidia o trabalho pedagógico, considerando que nas instituições a criança deve ter momentos prazerosos, ser respeitada por suas "diferenças individuais, sociais, econômicas, culturais, étnica, religiosas, etc" (BRASIL, 1998, p.13), garante o direito de brincar, expressar-se, pensar, interagir e se comunicar. Situações do cotidiano favorecem o trabalho com a Matemática (BRASIL, 1998). A exploração, manipulação dos objetos e brinquedos possibilitam a descoberta das caraterísticas e propriedades associativas, tais como: "empilhar, rolar, transvasar, encaixar" (BRASIL, 1998, p.218).

Sabe-se que mesmo as crianças mais novas possuem uma certa predisposição para lidar com quantidades, denominada senso numérico, e que problemas no senso numérico podem resultar em dificuldades no desenvolvimento do raciocínio matemático posterior e na aprendizagem da matemática formal (CORSO; DORNELES, 2010). O desenvolvimento do raciocínio matemático pela criança desde o senso numérico (sistema primário) até a aprendizagem da matemática formal (sistema secundário) - tem sido denominada de Cognição Numérica (SANTOS et al., 2016), e acredita-se que sua compreensão seja de extrema importância para o professor que ensina Matemática na Educação Infantil e Ensino 
Em uma revisão sobre o ensino da Matemática na Educação Infantil, Sanchez Junior; Blanco e Coelho Neto (2017) identificaram que os trabalhos voltados para essa área são, em sua maioria, pesquisas teóricas, que discutem a formação inicial e continuada dos professores e os documentos oficiais que normatizam a Educação Infantil no Brasil, mas não apresentam propostas para o ensino da Matemática nem para a formação desses professores.

Sendo assim, o objetivo geral desta pesquisa consiste em descrever a elaboração e a implementação da Produção Técnica Educacional: "Manual llustrado: Um guia prático e visual para o ensino da Matemática na Educação Infantil à partir da compreensão da Cognição Numérica" (SANCHEZ JÚNIOR, BLANCO, 2018), resultante de trabalho de conclusão de Mestrado Profissional em Ensino, discutindo a aplicabilidade de suas atividades e analisando a percepção dos professores da educação Infantil quanto a sua contribuição para sua prática de ensino e seus conhecimentos em relação à Cognição Numérica.

\section{O ENSINO DA MATEMÁTICA NA EDUCAÇÃO INFANTIL E O MODELO DA COGNIÇÃO NUMÉRICAO}

Segundo Cole e Cole (2003), a partir da década de 80 muitos pesquisadores começaram a sugerir que os bebês já nascem com um entendimento rudimentar de alguns conceitos básicos, ou apresentam, pelo menos, uma predisposição inata para adquirir esses conceitos, dentre eles o número.

Nessa perspectiva, relacionada à Psicologia Cognitiva e também à Neurociência, entende-se que a matemática mais complexa e abstrata evolui de uma matemática mais simples, de origem biológica, a partir do desenvolvimento da contagem. A Cognição Numérica se constitui de um sistema primário, o Senso Numérico, e sistemas secundários como o Processamento Numérico, o qual se subdivide em Compreensão Numérica (entendimento dos símbolos numéricos) e Produção Numérica (leitura, escrita e contagem de números) e o Cálculo (operações matemáticas), sendo influenciada por fatores biológicos, cognitivos, educacionais e culturais (MOLINA, et al., 2015).

O desenvolvimento do raciocínio matemático pela criança - desde o senso numérico (sistema primário) até a aprendizagem da matemática formal (sistema secundário) - tem sido denominada de Cognição Numérica (SANTOS et al.; 2016), e acredita-se que sua compreensão seja de extrema importância para o professor que ensina matemática na Educação Infantil e Ensino Fundamental.

Dehaene e Naccache (2001) afirmam que o senso numérico é a capacidade do indivíduo em compreender rapidamente, aproximar e manipular quantidades numéricas. É a capacidade mais básica e inata de reconhecer, representar, comparar, estimar, julgar magnitudes não verbais, somar e subtrair números sem a utilização de recursos de contagem, presente em todo ser humano, ainda em seu primeiro ano de vida, e também em alguns animais (DEHAENE; NACACCHE, 2001, DEHAENE, 1997).

Segundo Von Aster e Shalev (2007), o senso numérico é entendido como a habilidade de representar e manipular magnitudes numéricas não verbais em uma linha numérica mental, orientada espacialmente, que seria a capacidade de ordenar as quantidades em um contínuo (de zero a infinito). De acordo com Silva; Ribeiro e Santos (2015), a Linha Numérica Mental vai sendo desenvolvida a partir 
das experiências da criança e da escolarização e permite que ela compreenda, aproxime e manipule quantidades maiores. É o desenvolvimento dessa linha numérica mental que marca a passagem das habilidades inatas para as habilidades matemáticas secundárias.

De acordo com Geary (2000), as habilidades secundárias são dependentes da escolarização, e incluem o conceito de número, contagem e a aritmética (cálculo e problemas verbais). Para Gelman e Gallistel (1978), a contagem é guiada por um conhecimento inato, que os autores denominaram de princípios de contagem. Esses princípios são cinco: correspondência de um-para-um (entendimento de que cada objeto é contado apenas uma vez); ordem estável (uso dos numerais em ordem fixa); cardinalidade (a quantidade de objetos significa o último numeral falado); irrelevância da ordem de contagem (qualquer ordem de realizar a contagem não altera o resultado); generalização (o mesmo princípio de contagem para conjuntos de quaisquer elementos) (GELMAN; GALLISTEL, 1978).

De acordo com o modelo proposto por McCloskey, Caramazza e Basili (1985), as habilidades matemáticas secundárias se dividem em dois sistemas: o sistema de processamento numérico e o sistema de cálculo. 0 sistema de processamento numérico inclui os mecanismos de compreensão numérica e produção numérica, enquanto o sistema de cálculo consiste em fatos e procedimentos necessários para a realização dos cálculos.

Assim, entendemos que a matemática é algo bastante complexo, sendo que seus mecanismos cognitivos incluem o senso numérico, o conhecimento do sistema numérico, representação simbólica e não simbólica, comparar e estimar quantidades, processos fonológicos, inteligência, velocidade de processamento, memória de trabalho e funções executivas, e podem ser afetadas pelas estratégias que se usam para o ensino (HAASE et al., 2014).

No Brasil, o ensino da Matemática na Educação Infantil tem como documento norteador o Referencial Curricular Nacional para a Educação Infantil - RCNEI (BRASIL, 1998). Este documento propõe como objetivo proporcionar oportunidades para que as crianças desenvolvam capacidade de estabelecer aproximações e relações com o seu cotidiano como: contagem, relações espaciais, reconhecer e valorizar números, contar oralmente e comunicar ideias matemáticas.

As noções matemáticas são construídas pela criança a partir das suas relações com o meio, ou seja, suas experiências e interações. Por isso, em sala de aula, é imprescindível que o professor ofereça e possibilite inúmeras e distintas situações para construção de significados (BRASIL, 1998; LORENZATO, 2006), destacando que as Diretrizes Curriculares Nacionais para Educação Infantil (BRASIL, 2010) fixam como eixos norteadores para as práticas pedagógicas da Educação Infantil as interações e as brincadeiras.

Ao considerar as transformações na sociedade, reformas educacionais e dados que revelam baixos índices escolares dos alunos, a exigência de uma formação de qualidade é cada vez maior, sendo imprescindível que se tenha acesso a programas de formação continuada, com o objetivo de desenvolvimento profissional e melhoria na qualidade do ensino (PRADO; FERREIRA, 2016).

O professor da Educação Infantil é tratado pelos pesquisadores em Educação Matemática como "professores que ensinam Matemática", ou seja, professores 
polivalentes que ensinam a Matemática apesar de não serem denominados "professores de Matemática" e nem serem especialistas. Nacarato e Paiva (2008), bem como Sanchez Junior; Blanco e Coelho Neto (2017) destacam que poucas pesquisas têm se voltado a esses profissionais, e afirmam ser este um campo bastante amplo para pesquisa.

Barbosa e Horn (2008), ao tratar dos conhecimentos matemáticos específicos, consideram a formação do professor da Educação Infantil ainda precária, pois os cursos de formação priorizam as disciplinas de fundamentos, e assim, na prática dos professores há muito "senso comum, com conhecimentos simplórios, muitas vezes que adquiriram em sua própria infância, isto é, conhecimento desatualizado, fragmentado e óbvio" (BARBOSA; HORN, 2008, p. 40).

Assim, entende-se que a compreensão do desenvolvimento das habilidades da Cognição Numérica seja de extrema importância para a prática do professor que ensina matemática na Educação infantil, para que o ensino aconteça com qualidade. Então, a elaboração do Manual "Um guia prático e visual para o Ensino da Matemática na Educação Infantil à partir da compreensão da Cognição Numérica" tem o objetivo de contribuir para entendimento, por parte dos professores, de como se dá o desenvolvimento da Cognição Numérica nas crianças e propor atividades que possam auxiliar sua prática de ensino dos conteúdos matemáticos.

\section{ELABORAÇÃO DO MANUAL E DO CURSO DE CAPACITAÇÃO}

O Manual Ilustrado "Um guia prático e visual para o Ensino da Matemática na Educação Infantil à partir da compreensão da Cognição Numérica" foi elaborado a partir dos pressupostos da Psicologia Cognitiva e do Modelo da Cognição Numérica, assim como dos documentos oficiais que orientam a prática pedagógica na Educação Infantil, com atividades que visam contribuir com o desenvolvimento da Cognição Numérica e o ensino da matemática na Educação Infantil, de forma lúdica. Portanto, sua elaboração deu-se a partir da análise dos conteúdos de Matemática da Educação Infantil propostos pela Secretaria Municipal de Educação de Cornélio Procópio (PARANÁ, 2015), em consonância com as orientações do Ministério da Educação (MEC) pelo RCNEI (BRASIL, 1998), à luz da abordagem da Cognição Numérica proposta.

Configura-se como um produto educacional, resultante do trabalho de conclusão de um programa de Mestrado Profissional em Ensino, que têm como diferencial a produção de conhecimento aplicado, com o desenvolvimento de produtos e tecnologias educacionais e sociais, na modalidade Produção Técnica, sendo diferente da bibliográfica, ou seja, artigos, livros e outros (BRASIL, 2016).

A área de Ensino é essencialmente de pesquisa translacional, que busca pontes para aplicação em produtos e processos educativos na sociedade, e tem crescido devido à capacidade de respostas às demandas e desafios de qualificação de profissionais de Ensino Superior no Brasil (BRASIL, 2016). Sendo assim, além da produção bibliográfica, a área do Ensino tem valorizado o "desenvolvimento de materiais e processos educacionais, cursos de curta duração e atividades de extensão relacionadas à prática docente [...]" (BRASIL, 2016, p.9).

Tal produto educacional apresenta uma introdução teórica, assim como a proposta de 33 atividades para desenvolvimento do Senso Numérico, 
Processamento Numérico (Compreensão Numérica e Produção Numérica) e Cálculo. Em cada atividade são descritos seu objetivo e conteúdo trabalhado, os materiais utilizados, assim como sugestões de músicas para utilizarem nas atividades propostas ${ }^{2}$. Abaixo, seguem algumas imagens que ilustram o manual.

Figura 1 - Capa do Manual

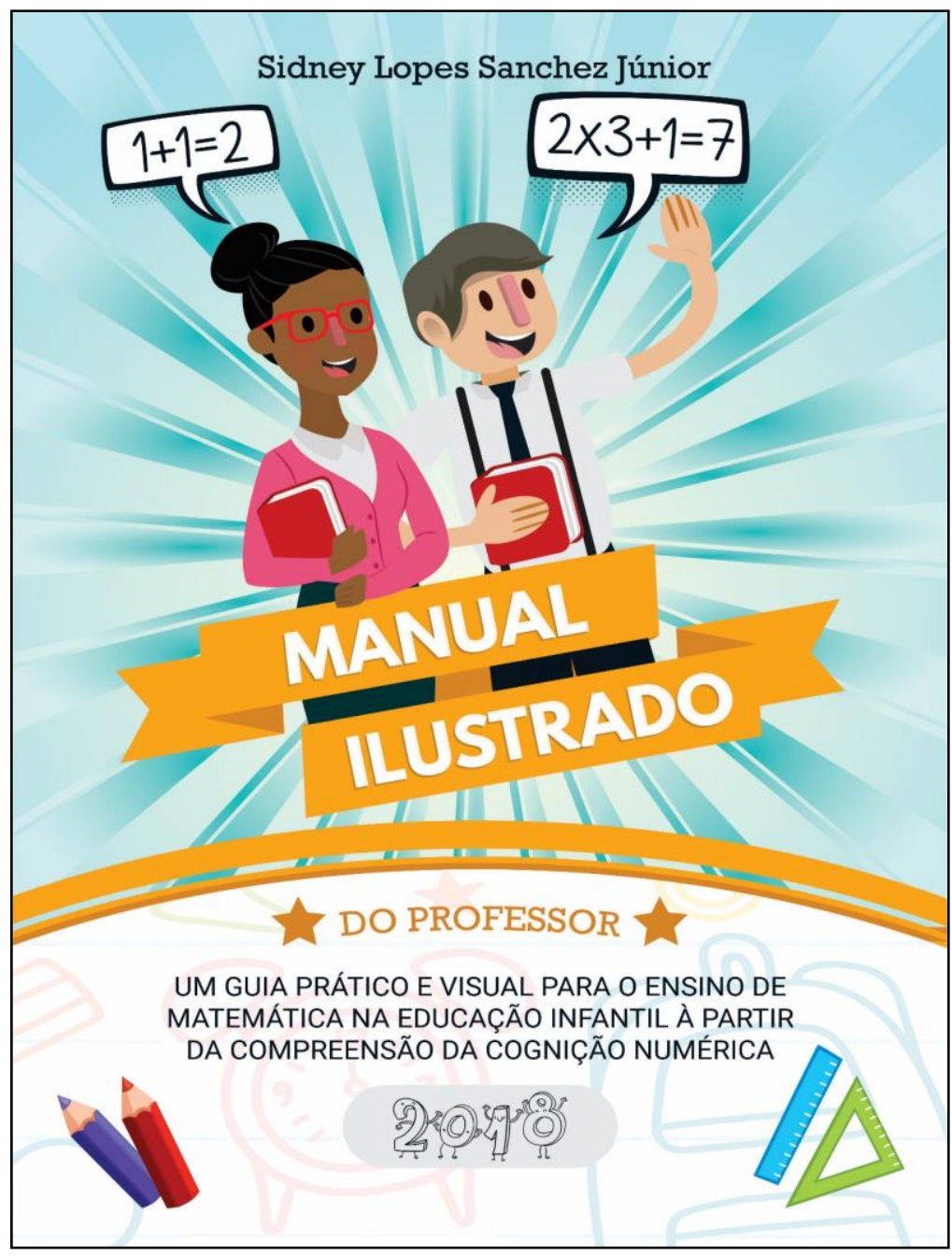

Fonte: Sanchez Júnior e Blanco (2018). 
Figura 2 - Atividade 5: Caracol

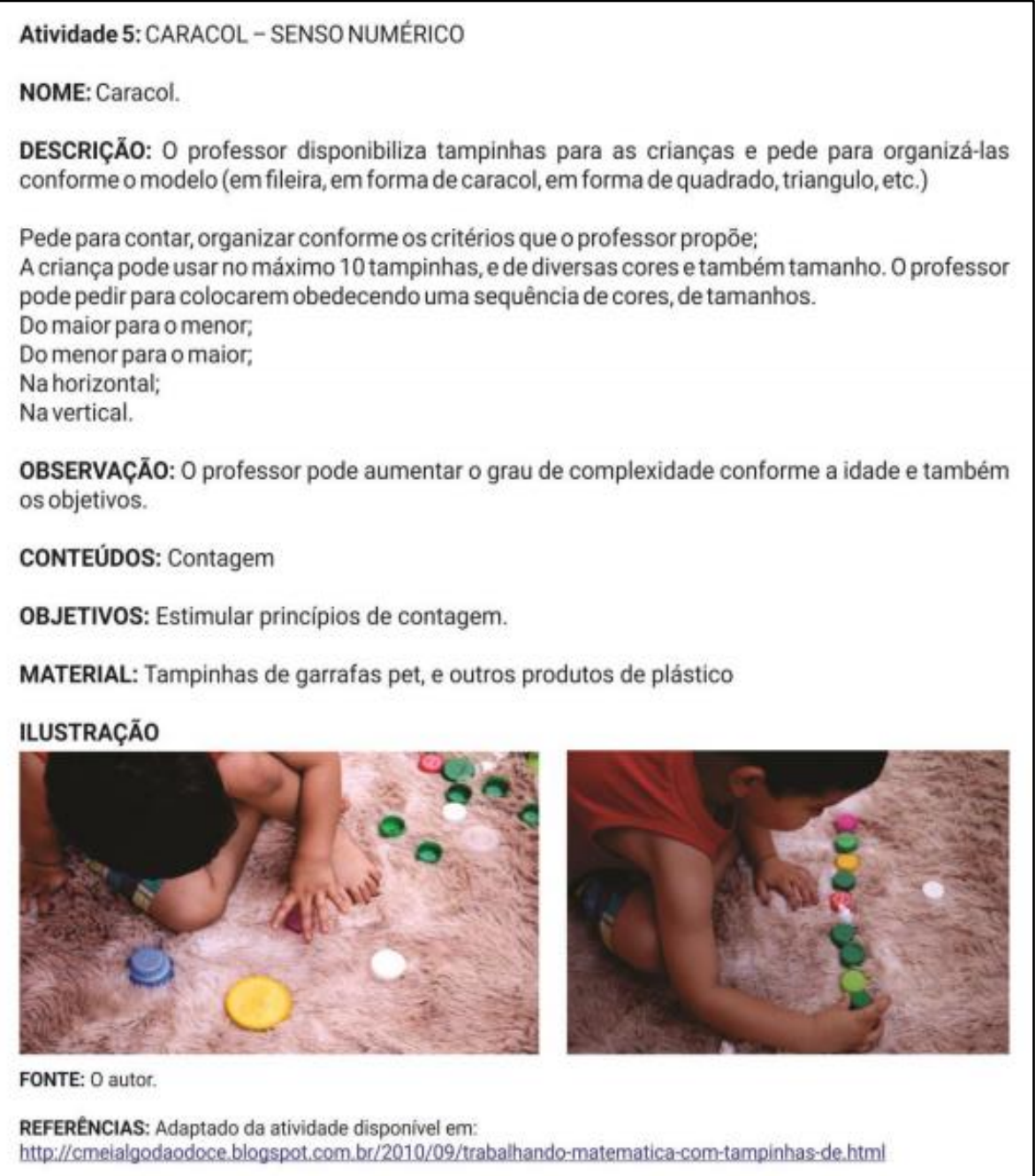

Fonte: Sanchez Júnior e Blanco (2018).

A atividade 5, 0 Caracol, ilustrada pela Figura 2, pode ser aplicada com as crianças da Educação Infantil de 0 a 5 anos de idade, desde que, quando muito pequena, receba acompanhamento e orientações de um indivíduo mais experiente ou o professor. Antes de contar, organizar e enfileirar as diversas tampinhas de garrafas, é importante que a criança pequena possa manusear e conhecer o material, a fim de compreender as instruções e realizar as solicitações dadas pelo professor. 
Figura 3 - Atividade 8: Cantando e aprendendo a sequência numérica

Atividade 8: CANTANDO E APRENDENDO A SEQUÊNCIA NUMÉRICA - COMPREENSĂO NUMÉRICA

NOME: Cantando e aprendendo a sequência numérica.

DESCRIÇĀO: Ao cantar a "Música dos Números" sentadas em círculo, cada criança receberá uma figura em E.V.A. que colocará no bolso do avental numérico quando identifica-la na canção.

OBSERVAÇÃO: "Música dos Números" (Gugu Dadá)

FONTEDAMÚSICA: http://www.youtube.com/gugudadatv

CONTEÚDOS: Contagem oral;

OBJETIVOS: Estimular habilidades da Compreensão Numérica:

Estimular estratégias de contagem:

Contar oralmente até o 10;

Estimular correspondência de um para um, ordem estável, cardinalidade, irrelevância da ordem e a generalizaçāo;

MATERIAL: Avental Numérico, animais de E.V.A. "Música dos Numerais"

ILUSTRAÇÃo
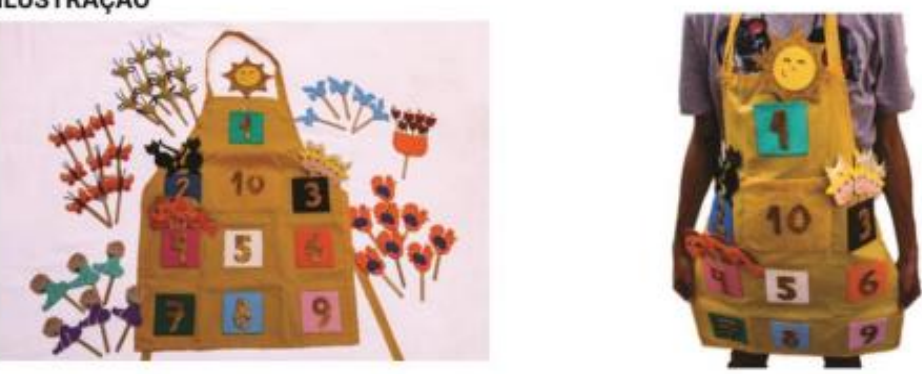

FONTE: 0 autor

REFERÊNCIAS: Atividade desenvolvida pelo proprio autor, tendo como base a música Numerais (Gugu Dadá),

Fonte: Sanchez Júnior e Blanco (2018).

A atividade 8, intitulada "Cantando e aprendendo a sequência numérica", ilustrada na Figura 3, pode ser aplicada com crianças da Educação Infantil de 0 a 5 anos, desde que o professor proponha situações com níveis de complexidade menor ou maior, de acordo com os objetivos a serem desenvolvidos. Esta atividade estimula o desenvolvimento dos princípios da Contagem, uma vez que crianças muito pequenas desenvolvem essa habilidade juntamente com a linguagem, seguidos da Compreensão e Produção Numérica. A música indicada no material pode ser encontrada no link indicado nas notas. ${ }^{3}$ 
Figura 4 - Atividade 9: Matando a fome do tubarão

Atividade 9: MATANDO AFOMEDOTUBARÃO - COMPREENSÃO NUMÉRICA

NOME: Matando a fome do tubarāo.

DESCRIÇÃO: Após lançar o dado de quantidades, a criança deve identificar as quantidades e colocar os peixinhos na boca do tubarão.

O professor diz às crianças que o Tubarão está com muita fome, e precisa ser alimentado.

SUGESTĀO MUSICAL: Lá vem o Tubarăo(Letra/Melodia: Fernanda Carolina)

FONTE:http:///orgulhodesereducador.blogspot

CONTEÚDOS: Contagem oral;

OBJETIVOS: Estimular habilidades da Compreensão Numérica:

Estimular a representaçăo simbólica visual, verbal auditivo e representação analógica de magnitudes:

MATERIAL: Tubarăo pode ser confeccionado com papelão, cartolina, papel cartão e os peixinhos de E.V.A e um dado de quantidades.

ILUSTRAÇĀO

FONTE: 0 autor.
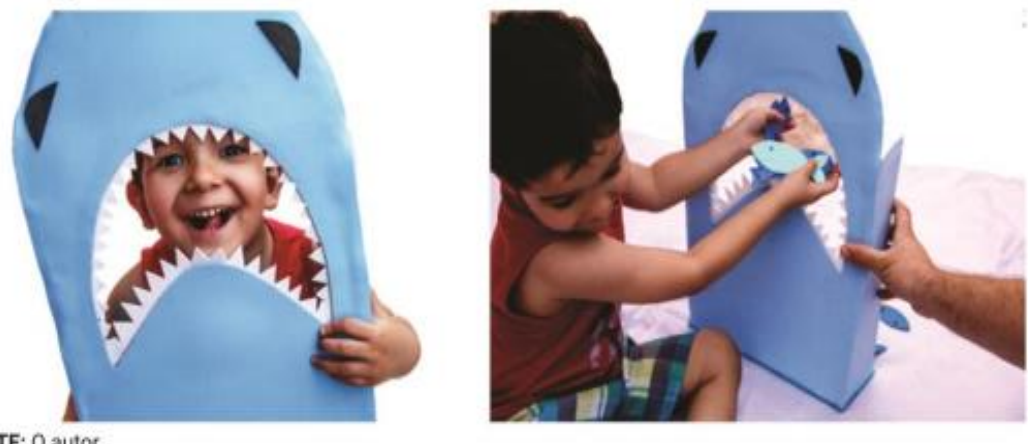

REFERÊNCIAS: Adaptado da atividade disponivel em: www. editodabrasil.com.br

Fonte: Sanchez Júnior e Blanco (2018).

A atividade 9, intitulada "Matando a fome do Tubarão", ilustrada pela Figura 4, pode ser aplicada com crianças da Educação Infantil de 0 a 5 anos, desde que o professor proponha situações com níveis de complexidade menor ou maior, de acordo com os objetivos a serem desenvolvidos. Esta atividade estimula o desenvolvimento dos princípios da Contagem, uma vez que crianças muito pequenas desenvolvem essa habilidade juntamente com a linguagem, seguidos da Compreensão e Produção Numérica (MARCILESE, 2012). 
Figura 5 - Atividade 16: Meus Cupcakes de aniversário

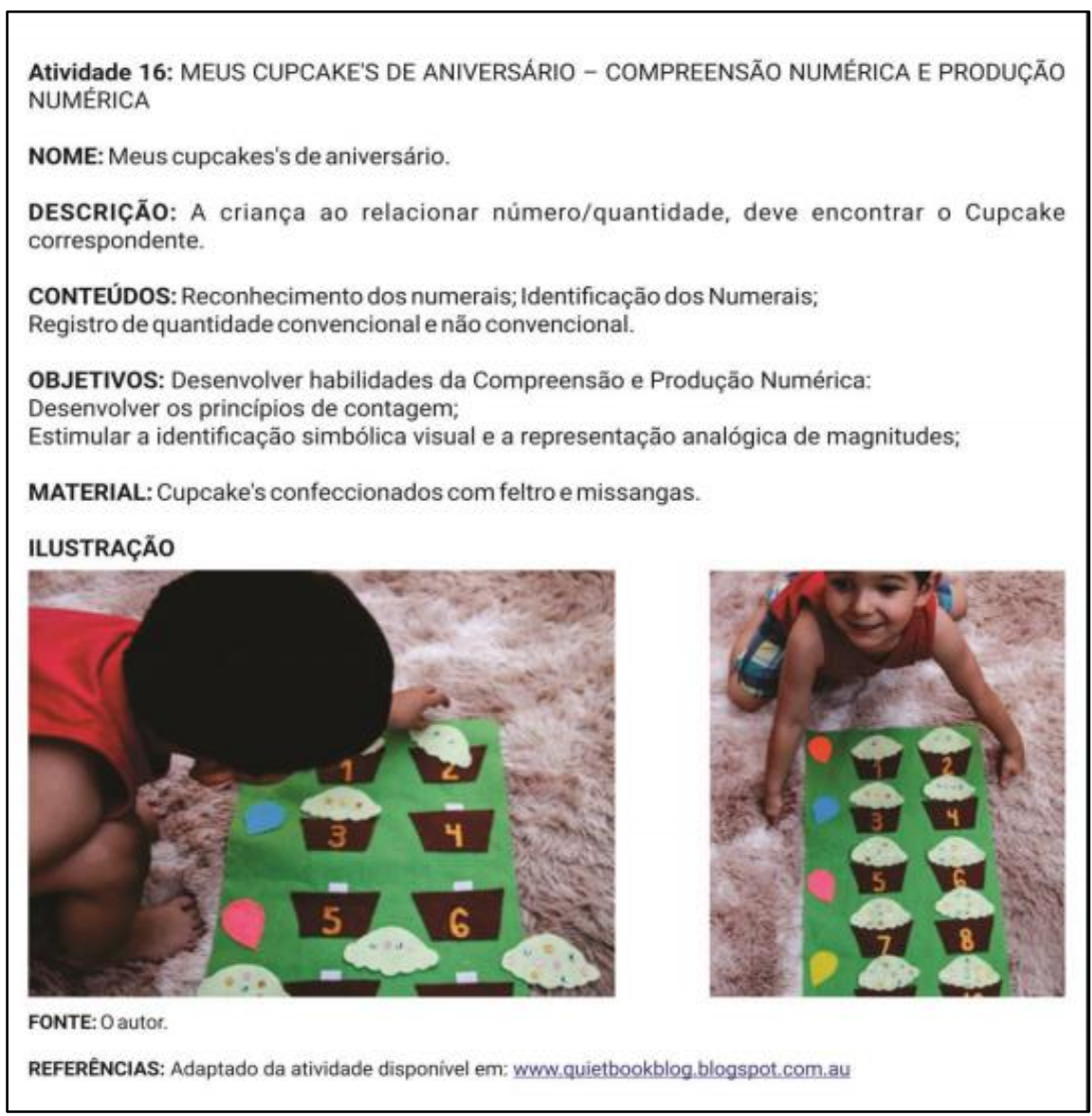

Fonte: Sanchez Júnior e Blanco (2018).

As atividades propostas no Manual llustrado foram aplicadas em um curso de capacitação para as professoras da Educação Infantil, com objetivo de iniciar um processo de validação das mesmas e verificar sua aplicabilidade nas aulas de Matemática na Educação Infantil.

O curso de capacitação "O ensino da Matemática na Educação Infantil e o desenvolvimento da Cognição Numérica" contou com a participação de oito professoras da Educação Infantil da rede municipal de Cornélio Procópio, região norte do Estado do Paraná, sendo dividido em cinco encontros, nos quais as participantes puderam realizar as atividades propostas no manual, bem como contribuir para o melhoramento das atividades. As participantes assinaram um termo de consentimento livre esclarecido, participaram de uma entrevista individual semiestrutura, seguida dos cinco encontros presenciais.

Nos dois primeiros encontros do curso, as participantes conheceram e realizaram as atividades que compõem o produto educacional, com objetivo de validar as atividades e verificar a aplicabilidade na Educação Infantil. Nesta etapa, as participantes sugeriram alterações nas atividades que foram acatadas para melhorar a aplicabilidade do produto educacional.

O terceiro encontro teve caráter teórico, no qual o conteúdo foi exposto de forma oral, dando abertura para as participantes exporem suas dificuldades em relação ao ensino e a aprendizagem das crianças sobre os conteúdos matemáticos. O quarto encontro foi destinado a abordar os conteúdos que envolvem a Cognição 
Numérica, os modelos de compreensão da Cognição Numérica bem como os autores que embasam esta discussão, a fim de que as atividades propostas fossem compreendidas a partir deste campo teórico. Posteriormente, as participantes do curso analisaram o currículo de Matemática da cidade em que lecionam, buscando relação com as habilidades que devem ser desenvolvidas de acordo com os Modelos de Desenvolvimento da Cognição Numérica. No quinto e último encontro, as participantes relataram as experiências ao aplicar a atividade selecionada do produto educacional que teve como objetivo verificar as possíveis contribuições do curso para a formação das participantes, bem como as percepções positivas e negativas em relação ao material apresentado. Ao término do último encontro, as participantes responderam a um questionário final.

O detalhamento do curso segue apresentado no Quadro 1 abaixo:

Quadro 1 - Descrição do curso de capacitação

\begin{tabular}{|c|c|c|}
\hline Encontro & Objetivo & Encaminhamentos \\
\hline Encontro 1 & $\begin{array}{c}\text { Realizar as atividades } \\
\text { propostas no Manual } \\
\text { Ilustrado e validar as } \\
\text { mesmas pelas } \\
\text { professoras } \\
\text { participantes. }\end{array}$ & $\begin{array}{l}\text { Inicialmente foram dadas as boas-vindas e } \\
\text { agradecimentos aos professores inscritos, } \\
\text { seguidas da explicação de que o curso faz parte } \\
\text { de uma pesquisa de Mestrado do programa de } \\
\text { Pós-Graduação Stricto Senso em Ensino pela } \\
\text { Universidade Estadual do Norte do Paraná. } \\
\text { Desta forma, foi enfatizado o caráter } \\
\text { teórico/prático do curso e que a participação } \\
\text { com assiduidade e compromisso é de extrema } \\
\text { importância. } \\
\text { A dinâmica inicial foi realizada com a música } \\
\text { "Por dentro, fora, alto, baixo, sempre sou feliz" } \\
\text { de autoria de "Três Palavrinhas", disponível em } \\
\text { (https://youtu.be/s3Mvl9xvKRs), visando a } \\
\text { socialização dos professores participantes e } \\
\text { abordando os conteúdos de lateralidade, } \\
\text { dentro, fora, alto, baixo, coordenação motora e } \\
\text { esquema corporal. } \\
\text { Posteriormente, foi apresentado às } \\
\text { participantes o produto educacional, com as } \\
\text { atividades para o Ensino de Matemática na } \\
\text { Educação Infantil. } \\
\text { Foram realizadas } 10 \text { atividades antes do } \\
\text { intervalo e } 10 \text { após, totalizando } 20 \text { atividades } \\
\text { neste primeiro encontro }\end{array}$ \\
\hline Encontro 2 & $\begin{array}{c}\text { Realizar as atividades } \\
\text { propostas no produto } \\
\text { educacional e validar } \\
\text { as mesmas pelas } \\
\text { professoras } \\
\text { participantes. }\end{array}$ & $\begin{array}{l}\text { Encaminhamentos Metodológicos: Início com a } \\
\text { recepção das professoras com dinâmica a partir } \\
\text { da música “Os números” (Fonte: } \\
\text { https://youtu.be/iB-f_SMQ_20) com objetivo } \\
\text { de socialização e reflexão sobre a importância } \\
\text { da atividade lúdica e a presença da música na } \\
\text { prática do professor, abordando o conteúdo de } \\
\text { contagem oral. Ao retomar ao produto } \\
\text { educacional, foram executadas as } 21 \text { atividades } \\
\text { restantes. }\end{array}$ \\
\hline
\end{tabular}




\begin{tabular}{|c|c|c|}
\hline Encontro 3 & $\begin{array}{l}\text { Identificar quais } \\
\text { fatores as professoras } \\
\text { associam à } \\
\text { Matemática, por meio } \\
\text { de mapa mental; } \\
\text { discutir o ensino da } \\
\text { Matemática na } \\
\text { Educação Infantil. }\end{array}$ & $\begin{array}{l}\text { Iniciou-se com uma brincadeira cantada “Pano } \\
\text { Encantado" (Fonte: } \\
\text { https://youtu.be/H7IUS4BkOYI) com objetivo } \\
\text { de descontração e socialização, estimulando a } \\
\text { musicalidade. } \\
\text { Em seguida, foram distribuídas folhas sulfite e } \\
\text { também lápis de cor e canetas coloridas para } \\
\text { realização de seu mapa mental individual, a } \\
\text { partir da palavra “Matemática”. Após a } \\
\text { elaboração dos mapas, estes foram } \\
\text { apresentados pelas professoras. } \\
\text { Posteriormente foi feita uma discussão sobre a } \\
\text { importância da brincadeira e o lúdico no ensino } \\
\text { da Matemática na Educação Infantil, com base } \\
\text { em trechos dos documentos oficiais. As } \\
\text { participantes relataram suas experiências, bem } \\
\text { como as dificuldades para o ensino e a } \\
\text { aprendizagem dos conteúdos de Matemática. } \\
\text { Após a discussão, as participantes selecionaram } \\
\text { uma atividade do produto educacional a ser } \\
\text { aplicada em seus alunos durante a semana. }\end{array}$ \\
\hline Encontro 4 & $\begin{array}{l}\text { Abordar os conteúdos } \\
\text { relacionados à } \\
\text { Cognição Numérica; } \\
\text { analisar dos Conteúdos } \\
\text { da Educação Infantil, } \\
\text { pela compreensão da } \\
\text { Cognição Numérica. }\end{array}$ & $\begin{array}{c}\text { Iniciou-se com a exposição oral sobre a } \\
\text { cognição numérica: Modelo da Cognição } \\
\text { Numérica (Santos, et al, 200, 2016); Modelo } \\
\text { Triplo Código de Dehaene (1997, 2001), Modelo } \\
\text { de Desenvolvimento das Habilidades da } \\
\text { Cognição Numérica de Von Aster e Shalev } \\
\text { (2007) e Menon (2010), com utilização de data- } \\
\text { show e caixa de som. } \\
\text { Posteriormente, em grupos, foram analisados } \\
\text { os conteúdos da Educação Infantil da cidade de } \\
\text { Cornélio Procópio identificando os as } \\
\text { habilidades da Cognição Numérica bem como } \\
\text { os modelos apresentados pelos autores citados } \\
\text { a cima. }\end{array}$ \\
\hline Encontro 5 & $\begin{array}{c}\text { Discutir sobre a } \\
\text { percepção das } \\
\text { professoras sobre a } \\
\text { aplicação da atividade } \\
\text { escolhida do produto } \\
\text { educacional e a } \\
\text { contribuição do curso } \\
\text { no processo de } \\
\text { formação. }\end{array}$ & $\begin{array}{l}\text { O encontro foi iniciado com a exposição oral } \\
\text { das participantes sobre suas experiências, } \\
\text { relatando e compartilhando com os demais } \\
\text { sobre a atividade aplicada em sala de aula. As } \\
\text { participantes responderam o questionário final } \\
\text { para avaliação do curso e encerrou-se com os } \\
\text { agradecimentos. }\end{array}$ \\
\hline
\end{tabular}

Fonte: Autores (2018).

Os dados analisados no presente artigo foram obtidos por meio de: 1) entrevista inicial; 2) da participação durante o curso; 3) das exposições sobre a implementação das atividades em sala de aula e 4) dos questionários finais, e foram analisados a partir dos pressupostos da Análise Textual Discursiva (ATD) (MORAES; GALIAZZI, 2014).

A Análise Textual Discursiva corresponde a um conjunto de métodos variados, analisando informações de forma qualitativa, com a finalidade de produzir novas compreensões sobre os fenômenos e discursos (MORAES; GALIAZZI, 2014). Este 
processo acontece em quatro momentos: desconstrução e unitarização do corpus, no qual, a partir da fragmentação dos textos, surgem unidades de análise, que podem ser definidas a priori ou podem emergir a partir da análise; processo de categorização, com o estabelecimento das relações entre as unidades, formando as categorias de análise; construção do metatexto analítico, com a descrição e interpretação dos textos, a partir da teorização; e a emergência do novo, com a comunicação da nova compreensão do fenômeno (MORAES, 2003). As categorias a priori, segundo Moraes (2003), correspondem as construções do pesquisador que são elaboradas à partir das teorias que fundamentam o trabalho; já as emergentes são construções a partir das informações do corpus, e estão associadas aos métodos indutivos e intuitivos.

As categorias Conhecimento sobre a Cognição Numérica e Produto Educacional, analisadas no presente artigo, foram elencadas a priori, a partir da fundamentação teórica que sustenta a pesquisa, com objetivo de identificar as percepções das participantes quanto ao conhecimento sobre a Cognição Numérica e da contribuição do produto educacional para sua prática pedagógica.

Figura 6 - Categoria Cognição Numérica e unidades de análise elencadas a priori

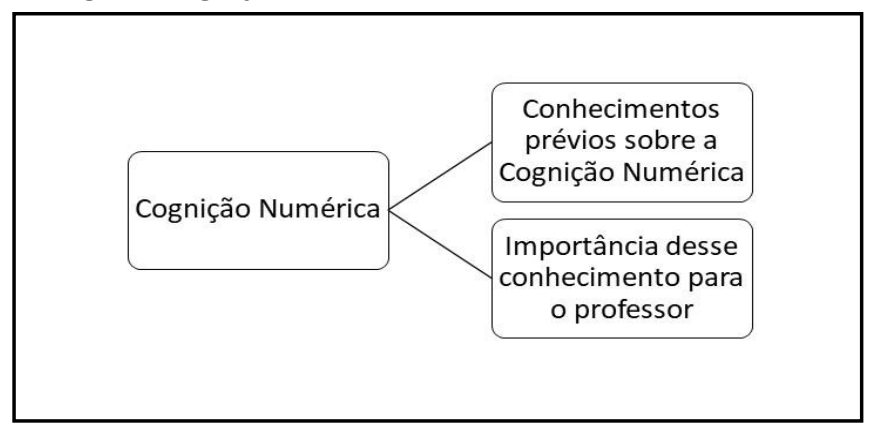

Fonte: Autores (2018).

Figura 7 - Categoria Produto Educacional e unidades de análises elencadas a priori

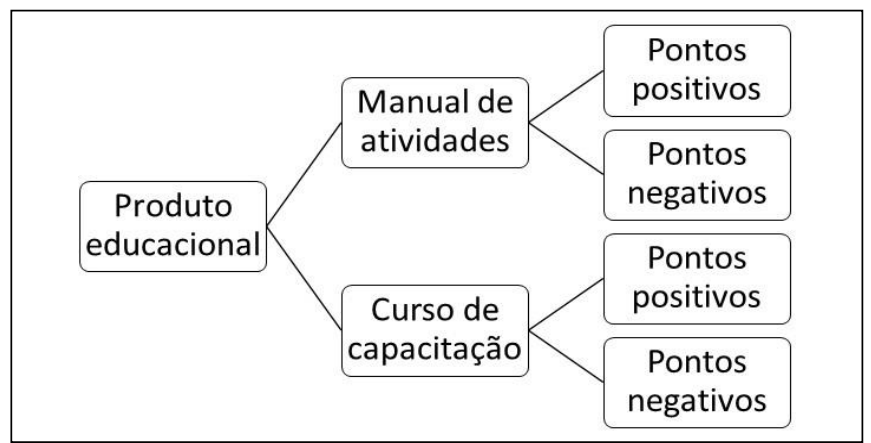

Fonte: Autores (2018).

Assim, os resultados descritos a seguir dizem respeito ao conhecimento das professoras participantes quanto à Cognição Numérica e as percepções positivas e negativas das mesmas acerca do Curso de Capacitação proposto às participantes, intitulado "O ensino da Matemática na Educação Infantil e a compreensão da Cognição Numérica" e do Manual llustrado "Um guia prático e visual de atividades para o Ensino da Matemática na Educação Infantil, a partir da compreensão da Cognição Numérica". 


\section{RESULTADOS DA IMPLEMENTAÇÃO}

As participantes foram oito professoras da Educação Infantil municipal, com idades entre 29 a 55 anos e tempo de atuação na Educação Infantil entre três a onze anos. No que diz respeito à formação, todas possuem curso superior, das quais 06 participantes são pedagogas, sendo que uma possui uma segunda graduação em Letras, 1 participante possui graduação em Administração de Empresas e 1 participante em Ciências com Habilitação em Física. Convém mencionar que a cursista formada em Administração de Empresas possui curso de formação de professores em nível médio, o que lhe permite atuação na Educação Infantil.

Sete participantes possuem pós-graduação latu sensu, em nível de especialização, sendo que uma encontra-se cursando Mestrado Profissional em Ensino e uma participante não relatou possuir pós-graduação. Ressalta-se que cinco participantes apresentam Especialização em Educação Infantil, duas em Educação Especial Inclusiva, uma em Aconselhamento Educacional Familiar e uma em Neuropsicopedagogia, sendo que duas participantes têm formação em dois cursos de especialização. Vale destacar, em relação à formação continuada na área do Ensino da Matemática, que todas as participantes relataram que não participaram de nenhum curso de formação voltado ao Ensino da Matemática nesses últimos anos.

A Categoria 1, conforme ilustra a Figura 6, contempla as percepções relacionadas aos conhecimentos sobre a Cognição Numérica, destacando na primeira unidade de análise os conhecimentos prévios sobre a Cognição Numérica, e a segunda unidade evidencia a importância desse conteúdo para o professor.

A seguir no Quadro 2, que representa a categoria Cognição Numérica, serão apresentados os excertos da unidade Conhecimentos Prévios sobre a Cognição Numérica.

Quadro 2 - Conhecimentos Prévios sobre a Cognição Numérica

\begin{tabular}{|c|c|c|}
\hline Categoria & Unidade & Excertos \\
\hline $\begin{array}{l}\text { Cognição } \\
\text { Numérica }\end{array}$ & $\begin{array}{c}\text { Conhecimentos } \\
\text { Prévios sobre a } \\
\text { Cognição } \\
\text { Numérica }\end{array}$ & $\begin{array}{l}\text { “Eu penso que cognição numérica é a parte } \\
\text { cognitiva, ou seja, que a criança tem em relação a } \\
\text { matemática, a questão de estrutura cognitiva do } \\
\text { cérebro" (participante P2). } \\
\text { “Não. Em minha formação inicial não teve } \\
\text { nenhuma disciplina que abordou esse } \\
\text { conhecimento" (participante P3). } \\
\text { “Não, não sei. Não, porque na minha grade de } \\
\text { Pedagogia na época, não fazia parte, então não era } \\
\text { trabalhado isso" (participante P4). } \\
\text { "Eu me lembro vagamente mas não lembro o que } \\
\text { significa [...] Eu me lembro que foi abordado nas } \\
\text { disciplinas de alfabetização, onde nós aprendemos } \\
\text { a alfabetização inicial de português e matemática, } \\
\text { mas eu não me lembro assim especificamente para } \\
\text { explicar pra você o que é” (participante P5). }\end{array}$ \\
\hline
\end{tabular}


"Não sei. Bom pra mim, a cognição numérica está relacionada com a sequência numérica, relação do número e quantidade" (participante $\mathrm{P7}$ ).

"Não sei. É a criança associar números com quantidades? Alguma coisa assim? Eu acho que em meu curso de formação inicial a gente trabalhou muita coisa de matemática, muitas disciplinas, algumas disciplinas abordavam atividades pra matemática eu acho" (participante P8).

Fonte: Autores (2018).

Das participantes, 03 relataram, com certa insegurança, que possuíam algum conhecimento sobre a Cognição Numérica, o que será exemplificado a partir do relato da P2.

Eu penso que cognição numérica é a parte cognitiva, ou seja, que a criança tem em relação a matemática, a questão de estrutura cognitiva do cérebro (participante P2).

A participante $\mathrm{P} 2$ relacionou, ainda, a Cognição Numérica com o cérebro, uma relação que tem recebido destaque na Neurociência Cognitiva. Sabe-se que pesquisas em neuroimagem identificaram as diferentes regiões cerebrais envolvidas no processamento numérico (SCHMITHORST; BROWN, 2004). Ainda, de acordo com Dehaene (1992), o cérebro manipula o conhecimento numérico de diferentes formas, e cada um desses tipos de processamento relaciona-se a áreas específicas do cérebro.

De forma geral, segundo Cosenza e Guerra (2011), a noção de quantidade relaciona-se com o lobo temporal, o hemisfério esquerdo calcula enquanto o direito faz estimativas, ambos os hemisférios identificam e comparam números, mas só o hemisfério esquerdo é capaz de decodificar a representação verbal dos algarismos. Assim, identifica-se que a afirmação de P2 vem ao encontro do que tem sido discutido atualmente, mas esta não demonstrou possuir conhecimento mais aprofundado sobre o assunto, uma vez que apenas mencionou o envolvimento do cérebro nesse processo.

As participantes P7 e P8, relacionaram a Cognição Numérica com o conhecimento de números, quantidades e sequência numérica, como exposto no excerto da P7.

Bom, pra mim, a cognição numérica está relacionada com a sequência numérica, relação do número e quantidade (participante P7).

Para Santos et al (2016), a Cognição Numérica consiste no desenvolvimento do raciocínio matemático pela criança, que compreende desde o Senso Numérico (sistema primário), até a aprendizagem da matemática formal (sistema secundário). Von Aster e Shalev (2007) afirmam que a presença do Senso Numérico nas crianças dá a elas capacidade de representar e manipular magnitudes numéricas não verbais em uma linha numérica mental, que se constrói a partir das experiências com a escolarização, que permite a compreensão, aproximação e manipulação de quantidades maiores (SILVA; RIBEIRO; SANTOS, 2015).

Assim, identifica-se, de forma bastante elementar, que três participantes apresentam conhecimentos sobre a Cognição Numérica, envolvendo a sequência 
numérica, relação número e quantidade e a relação cognição e matemática. No entanto, 5 participantes mencionaram não ter conhecimento deste conteúdo.

Apenas 2 participantes relataram que esse conhecimento pode ter sido abordado em seu curso de formação inicial (Pedagogia e Formação em Nível Médio), mas não se recordam para explicar com maiores detalhes:

Eu me lembro que foi abordado nas disciplinas de alfabetização, onde nós aprendemos a alfabetização inicial de português e matemática, mas eu não me lembro especificamente para explicar pra você o que é (participante P5).

Eu acho que em meu curso de formação inicial a gente trabalhou muita coisa de matemática, muitas disciplinas, algumas disciplinas abordavam atividades pra matemática eu acho (participante P8).

Para Santos et al (2016), a compreensão da Cognição Numérica é de extrema importância para o professor que ensina matemática na Educação Infantil e no Ensino Fundamental. No entanto, evidenciou-se que a maioria das participantes não tiveram acesso a esse conteúdo, nem em sua formação inicial nem continuada.

Em relação à formação continuada, as participantes relataram que, durante sua atuação como professoras da Educação Infantil, nenhum curso abordando a temática do Ensino da Matemática na Educação Infantil foi ofertado. Sabendo desta importância, Araújo; Pereira e Dantas (2016) destacam que a formação inicial e continuada são processos interligados que capacitam o professor para melhor atuação, e a formação continuada visa o aperfeiçoamento profissional considerando o contexto do trabalho.

A formação continuada é necessária para que o professor responda as demandas no que tange aos conhecimentos teóricos e metodológicos, a fim de enriquecer a sua prática e complementar a formação inicial, que, na maioria das vezes, não dá subsídios ao professor para lidar com as inovações e desafios da sala de aula (ARAÚJO; PEREIRA; DANTAS, 2016). Em uma revisão, Sanchez Júnior; Blanco e Coelho Neto (2017) evidenciaram a necessidade da formação continuada para os professores que ensinam na Educação Infantil, sobretudo a disciplina de Matemática. Assim, destacamos a importância desse conteúdo ser abordado na formação inicial e continuada dos professores da Educação Infantil.

Desta maneira, é importante destacar a formação teórico e prática dos professores que ensinam Matemática na Educação Infantil, especialmente ao capacitá-los a pensar, planejar, refletir e estruturar intervenções pedagógicas de qualidade, que contribuam para melhorar a aprendizagem dos estudantes e diminuir as dificuldades de aprendizagem.

O Quadro 3 a seguir contempla a segunda unidade, relacionada a importância desse conteúdo para o professor. Os excertos representam as percepções que as participantes obtiveram sobre a importância dos conteúdos da Cognição Numérica para sua prática na Educação Infantil. 
Quadro 3 - A importância do conhecimento sobre a Cognição Numérica para o professor

\begin{tabular}{|c|c|c|}
\hline Categoria & Unidade & Excertos \\
\hline $\begin{array}{l}\text { Cognição } \\
\text { Numérica }\end{array}$ & $\begin{array}{l}\text { Importância do } \\
\text { conteúdo da } \\
\text { Cognição } \\
\text { Numérica para os } \\
\text { professores. }\end{array}$ & $\begin{array}{l}\text { "Os docentes saberem e dominarem as técnicas } \\
\text { que visem o aprendizado dos seus alunos é de } \\
\text { suma importância, pois de sua maneira de } \\
\text { aplicar, de seu conhecimento é que vai depender } \\
\text { o aprendizado do seu aluno" (participante P4). } \\
\text { "O docente precisa conhecer e dominar } \\
\text { conhecimentos sobre a Cognição Numérica para } \\
\text { trabalhar com seu aluno, pois este é essencial } \\
\text { para aprendizagens posteriores" (participante } \\
\text { P7). } \\
\text { "Se o professor não conhece aspectos } \\
\text { extremamente importantes para o } \\
\text { desenvolvimento do aluno, não saberá planejar } \\
\text { sua aula para solucionar as dificuldades dos seus } \\
\text { alunos" (participante P8). }\end{array}$ \\
\hline
\end{tabular}

Fonte: Autores (2018).

A partir dos resultados apresentados, identificamos que todas as participantes consideram importante o conhecimento sobre a Cognição Numérica, 03 participantes afirmam que esse conhecimento é importante para que o planejamento das atividades seja adequado.

\section{Se o professor não conhece aspectos extremamente importantes para o desenvolvimento do aluno, não saberá planejar sua aula para solucionar as dificuldades (participante P8).}

O Referencial Curricular Nacional para a Educação Infantil (BRASIL, 1998, p. 196) orienta ao professor a "[...] planejar uma sequência de atividades que possibilite aprendizagens significativas para as crianças, nas quais elas possam reconhecer os limites de seus conhecimentos, ampliá-los e/ou reformulá-los".

Desse modo, planejar possibilita oportunizar momentos de reflexão sobre as propostas curriculares e o cotidiano. Abuchaim (2012) destaca o planejamento como uma das principais ferramentas da prática docente, pois proporciona aperfeiçoamento da prática docente.

A fala da participante P7 também menciona as dificuldades na aprendizagem da matemática, e para Ciasca (2004), essas dificuldades podem estar relacionadas a diversos fatores, desde problemas no Sistema Nervoso Central, como falhas no processamento, no armazenamento de informações, mas também às privações socioeconômicas, culturais ou mesmo problemas pedagógicos, na maneira como se ensina a matemática (CIASCA, 2004).

As autoras Corso e Dorneles (2010) destacam que crianças com problemas no Senso Numérico podem apresentar dificuldades no desenvolvimento do raciocínio matemático posterior e na aprendizagem da Matemática formal. Isto posto, conhecimentos sobre a Cognição Numérica são de extrema importância para o planejamento de atividades que desenvolvam habilidades do senso numérico.

É importante ressaltar que, mesmo apresentando um conhecimento insuficiente sobre as habilidades da Cognição Numérica, as participantes o 
consideram de suma importância para o desenvolvimento da criança e também para o planejamento das atividades, como expressou a participante P7:

O docente precisa conhecer e dominar conhecimentos sobre a Cognição Numérica para trabalhar com seu aluno, pois este é essencial para aprendizagens posteriores.

Corso (2008) sugere a inclusão de tarefas escolares voltadas ao desenvolvimento do senso numérico, que formariam estruturas necessárias para o desenvolvimento do conceito de número, contagem e aritmética. E ainda, Geary (2000) reforça a ideia que as habilidades do senso numérico em manipular e discriminar elementos em um pequeno grupo formam estruturas para o desenvolvimento de conhecimentos matemáticos posteriores.

Assim, destaca-se a relevância do planejamento das atividades no ensino da Matemática na Educação Infantil e que o professor, ao conhecer o desenvolvimento da Cognição Numérica, tem subsídios para propor atividades que explorem habilidades básicas na criança, com objetivo de formar estruturas para aprendizagem de uma Matemática posterior, contribuindo, assim, para evitar possíveis dificuldades.

A Categoria 2, denominada Produto Educacional, compromete-se em analisar as percepções positivas e negativas acerca do Manual de atividades e do curso de capacitação proposto. O Quadro 4 a seguir apresenta as percepções das participantes quanto ao manual ilustrado:

Quadro 4 - Percepções das participantes acerca do Manual Ilustrado

\begin{tabular}{|c|c|c|c|}
\hline Categoria & \multicolumn{2}{|c|}{ Unidade } & Excertos \\
\hline $\begin{array}{c}\text { Produto } \\
\text { Educacional }\end{array}$ & $\begin{array}{l}\text { Manual de } \\
\text { Atividades }\end{array}$ & $\begin{array}{l}\text { Aspectos } \\
\text { Positivos }\end{array}$ & $\begin{array}{c}\text { O manual é um material riquíssimo que } \\
\text { nos trouxe uma infinidade de } \\
\text { possibilidades para trabalhar os } \\
\text { conteúdos de forma prática e lúdica" } \\
\text { (participante P1). } \\
\text { "[...]várias atividades que podem ser } \\
\text { aplicadas na Educação Infantil, com } \\
\text { boas referências e formas de utilizar" } \\
\text { (participante P2). } \\
\text { "Excelente material pedagógico, uma } \\
\text { ferramenta de uso diário para o } \\
\text { professor e aluno, que instiga e } \\
\text { desperta para o conhecimento e } \\
\text { aprendizado de ambos [...] me orientou } \\
\text { a trabalhar os conteúdos de forma } \\
\text { lúdica, despertando a curiosidade e } \\
\text { interesse dos alunos" (participante P3). } \\
\text { Antes, eu escolhia a atividade de } \\
\text { acordo com o planejamento e aplicava. } \\
\text { Hoje eu planejo e procuro qual objetivo } \\
\text { quero alcançar com o que planejei, aí } \\
\text { sim procuro a atividade que mais } \\
\text { aproxima do objetivo almejado" } \\
\text { (participante P6) }\end{array}$ \\
\hline
\end{tabular}




\begin{tabular}{|c|c|c|c|}
\hline & & $\begin{array}{l}\text { Aspectos } \\
\text { Negativos }\end{array}$ & $\begin{array}{l}\text { Acredito que algumas atividades não } \\
\text { seriam muito adequadas ao nível de } \\
\text { desenvolvimento hoje, mas não por } \\
\text { motivo do Manual, mas sim do nível } \\
\text { que se encontra a Educação Infantil } \\
\text { hoje no município (participante P2). } \\
\text { Parte escrita pequena, poderia explicar } \\
\text { mais cada atividade (participante P5). }\end{array}$ \\
\hline
\end{tabular}

Fonte: Autores (2018).

A partir dos resultados apresentados, foi possível identificar que os pontos positivos se sobressaíram aos pontos negativos, uma vez que todas as participantes elogiaram o material, considerando-o adequado para o ensino e rico em atividades práticas e lúdicas para auxílio do professor, como destacaram as participantes P1, P2 e P3. Vale apontar o excerto da participante P3:

[...] me orientou a trabalhar os conteúdos de forma lúdica, despertando a curiosidade e interesse dos alunos (participante P3).

Consoante às ideias de Macedo; Petty e Passos (2005), a presença do lúdico traz desafios, surpresas e curiosidades para as crianças.

A partir da percepção das participantes, como por exemplo o excerto da participante $\mathrm{P} 3$, as atividades do material despertam o interesse e curiosidade nas crianças, e Moreira (1999) assegura que uma das condições para ocorrer a aprendizagem significativa é o material ser relacionável à estrutura cognitiva do aprendiz, sendo assim, potencialmente significativo. Ainda, Rotta (2016) reitera que os métodos pedagógicos devem ser adequados a faixa etária da criança, para que ela tenha um bom aproveitamento.

Os pontos negativos foram apontados pelas participantes P2 e P5. A participante P2 não apontou as atividades propriamente ditas, mas sim o nível de desenvolvimento das crianças e exigência da Educação Infantil no município, e não entrou em maiores detalhes.

Já a participante P5 pontuou que as atividades deveriam ser melhores descritas e explicadas. Assim, a sugestão foi acatada e as alterações foram realizadas.

O produto educacional proposto teve como objetivo abordar os conteúdos e habilidades matemáticas requeridas nos Documentos oficiais que organizam e orientam o currículo na Educação Infantil. Desta maneira, ao submeter ao processo inicial de validação, aplicação e realização das atividades pelas professoras da Educação Infantil, pode-se adequar as atividades, a fim de que tornasse possível e viável sua implementação nas salas de aula da Educação Infantil na cidade locus da pesquisa e em todo Brasil.

A seguir, o Quadro 5 apresenta as percepções positivas e negativas a respeito do curso de capacitação. 


\begin{tabular}{|c|c|c|c|}
\hline Categoria & \multicolumn{2}{|c|}{ Unidade } & Excertos \\
\hline \multirow[t]{2}{*}{$\begin{array}{c}\text { Produto } \\
\text { Educacional }\end{array}$} & $\begin{array}{c}\text { Curso de } \\
\text { Capacitação }\end{array}$ & $\begin{array}{l}\text { Aspectos } \\
\text { Positivos }\end{array}$ & $\begin{array}{l}\text { Agora tenho maior compreensão de } \\
\text { cada fase que os alunos passam até } \\
\text { chegar em um conhecimento efetivo: } 1^{\circ} \\
\text { aprender o senso numérico, e só após } \\
\text { um trabalho bem completo, } \\
\text { desenvolverão os conceitos numéricos e } \\
\text { o cálculo" (participante P1). } \\
\text { "[...] várias atividades que podem ser } \\
\text { aplicadas na Educação Infantil, com } \\
\text { boas referências e formas de utilizar" } \\
\text { (participante P2). } \\
\text { "Excelente. Diversidade de atividades } \\
\text { lúdicas com objetivos alcançáveis dentro } \\
\text { da sala de aula" (participante P3). } \\
\text { “O curso foi excelente, trouxe atividades } \\
\text { diferenciadas na área da matemática, } \\
\text { podendo ensinar o aluno de forma } \\
\text { lúdica e prazerosa, que irá desenvolver } \\
\text { sua cognição numérica" (participante } \\
\text { P7). }\end{array}$ \\
\hline & & $\begin{array}{l}\text { Aspectos } \\
\text { Negativos }\end{array}$ & $\begin{array}{l}\text { "[...]as atividades do segundo dia do } \\
\text { curso não foram coerentes com o } \\
\text { desenvolvimento hoje da Educação } \\
\text { Infantil no município" (participante P2). } \\
\text { "[...]falta de interesse por parte dos } \\
\text { outros docentes, que não vieram" } \\
\text { (participante P5). }\end{array}$ \\
\hline
\end{tabular}

É importante ressaltar todas as participantes (8), destacaram pontos positivos em relação ao curso de capacitação, relatando que puderam ter uma melhor compreensão do desenvolvimento das habilidades numéricas na criança e realizaram várias atividades possíveis de serem aplicadas em sala de aula, favorecendo o desenvolvimento da Cognição Numérica.

A participante P1 relatou:

\begin{abstract}
Agora tenho maior compreensão de cada fase que os alunos passam até chegar em um conhecimento efetivo: primeiro aprender o senso numérico e só após um trabalho bem completo desenvolverão os conceitos numéricos e o cálculo (participante P1).
\end{abstract}

O desenvolvimento da Cognição Numérica, de acordo com Santos et al (2016), se dá desde o senso numérico até a aprendizagem da matemática formal. A compreensão deste conhecimento é de extrema importancia para o professor que ensina Matemática na Educação Infantil e Ensino Fundamental, assim como evidenciou a participante na fala acima.

Durante a implementação do curso houve a apresentação das atividades propostas no manual ilustrado. Assim, alguns participantes destacaram: 
[...] várias atividades que podem ser aplicadas na Educação Infantil, com boas referências e formas de utilizar (P2).

[...]diversidade de atividades lúdicas com objetivos alcançáveis dentro da sala de aula (P3).

[...]trouxe atividades diferenciadas na área da matemática, podendo ensinar o aluno de forma lúdica e prazerosa, que irá desenvolver sua cognição numérica (P7).

Os Documentos oficiais (BRASIL, 1998, 2010) enfatizam que o professor deve propor diferentes estratégias para o ensino, a fim de que a criança experimente novas formas de aprendizagem e possa avançar em suas descobertas, ao longo de vários dias, semanas ou meses.

A diversidade de atividades aludida pelas participantes P3 e P7 vai ao encontro da proposta de Lorenzato (2006), o qual afirma que, quanto maior for a vivência da criança, mais fácil aprenderá. Por este motivo, é imprescindível que o professor possibilite muitas e distintas situações e experiências, ressaltando a necessidade de retomada de tais situações em diferentes momentos. Deste modo, para este autor, torna-se evidente o uso de diferentes atividades e materiais didáticos para que a aprendizagem aconteça.

Ao explorar o desenvolvimento das habilidades da Cognição Numérica, como citou a participante P7, as dificuldades de aprendizagem da matemática formal podem ser diminuídas, pois são habilidades fundamentais requeridas no processamento numérico e em tarefas aritméticas (SANTOS et al., 2006).

Os aspectos negativos foram levantados pelas participantes P2 e P5. A participante P2 abordou o grau de exigência da Educação Infantil no município, que não está compatível com as atividades do segundo dia do curso. As atividades do segundo dia foram mais complexas, exigindo como pré-requisitos as habilidades primárias (Senso Numérico e Contagem). No entanto, de acordo com Molina, Ribeiro, Santos e Von Aster (2015), as crianças já possuem elementos rudimentares para desenvolver essas habilidades na fase pré-escolar. Os autores afirmam que, mesmo não completas, na Educação Infantil essas habilidades já estão presentes, e irão se desenvolver ao longo do Ensino Fundamental.

Destaca-se então, mais uma vez, a função dos Centros Municipais de Educação Infantil, que deixam de ser essencialmente assistencialista, e deve ater-se, também, ao ensino de conteúdos (MEDEIROS; RODRIGUES, 2014). Assim, cabe ao professor propor atividades que estimulem o desenvolvimento das habilidades numéricas.

Pode-se considerar, a partir de pesquisas realizadas por Sanchez Júnior; Blanco e Coelho Neto (2017) e Araújo, Pereira, Dantas (2016), a necessidade de propostas de estratégias/atividades para o ensino da Matemática na Educação Infantil e a formação dos professores que atuam nesta etapa da Educação, tanto no que se refere aos conhecimentos teóricos quanto aos metodológicos, para enriquecimento de sua prática.

Destaca-se, então, a importância da formação continuada, quando esta vem contribuir para a formação teórica e prática do profissional. A partir dos relatos 
das participantes da pesquisa, ao revelarem que o curso e o material proposto contribuíram para capacitação e formação continuada das professoras.

É evidente que os cursos de formação inicial de professores não dão conta de preparar os professores para todos os desafios da prática pedagógica, o que faz necessário o investimento em capacitação e formação continuada destes professores. Assim, destacamos a importância desta pesquisa, bem como sua implementação, aplicabilidade e a contribuição para o ensino da Matemática nesta etapa.

Ainda vale destacar as contribuições das pesquisas desenvolvidas pelos programas de Pós-Graduação profissional, ao buscarem não apenas a compreensão teórica, mas aproximar as produções à realidade educacional brasileira, o que contribui positivamente ao processo de melhoramento da qualidade da Educação.

\section{CONSIDERAÇÕES FINAIS}

A Matemática não é algo tão simples, todavia está presente na vida do ser humano desde o nascimento; e mesmo este sendo dotado de um conhecimento matemático inato e simples, é no processo de escolarização que são desenvolvidas habilidades mais complexas. Por isso, este trabalho visou contribuir com a prática do professor, afim de lhe fornecer subsídios para intervir de maneira adequada no ensino da Matemática, e acredita-se que, a partir do conhecimento da Cognição Numérica, o professor da Educação Infantil pode propor atividades para a aprendizagem da matemática, podendo também contribuir para que as dificuldades de aprendizagem sejam diminuídas.

É importante destacar que as habilidades primárias estão presentes nas crianças antes mesmo de qualquer instrução formal em aritmética, e que a aquisição da Cognição Numérica ocorre paulatinamente ao desenvolvimento cognitivo e acadêmico. Desta maneira, é importante perceber que o ensino deve acontecer de forma progressiva, considerando o Senso Numérico, a Compreensão Numérica, Produção Numérica e o Cálculo. Também se enfatiza a importância de vincular à Matemática ao cotidiano, ou seja, às vivências dos alunos, e a apresentação dos conteúdos de diferentes formas, para sua melhor apropriação. Compreender como se dá o desenvolvimento da cognição numérica proporciona ao professor um planejamento mais objetivo e mais clareza ao ensinar Matemática.

Sanchez Junior, Blanco e Coelho Neto (2017) evidenciaram uma escassez de propostas voltadas ao ensino da Matemática na Educação Infantil, sendo assim, este trabalho buscou desenvolver um material para dar suporte aos professores em suas práticas de ensino, sobretudo por tornar o conhecimento da Cognição Numérica acessível a estes, visando contribuir significativamente para sua prática.

Destarte, ao retomar o objetivo geral da presente pesquisa, o qual consistiu na elaboração de um manual ilustrado para o ensino da Matemática na Educação Infantil, assim como implementá-lo por meio de um curso de capacitação para os professores dos Centros Municipais de Educação Infantil da cidade de Cornélio Procópio, Paraná, identificou-se que este contribuiu para a formação continuada e para a prática dos professores. E espera-se que, a partir do curso de formação, 
bem como da utilização das atividades propostas na prática de ensino de Matemática na Educação Infantil, a aprendizagem desse conteúdo seja efetiva.

Em suma, os resultados da pesquisa revelam uma análise positiva do trabalho desenvolvido, aferindo que o Manual Ilustrado é aplicável na Educação Infantil, e pertinente à realidade dos Centros Municipais de Educação Infantil (CMEIS), constituindo-se de um material facilitador e potencializador de aprendizagem, bem como na formação de professores.

O fato desta pesquisa revelar obstáculos, como por exemplo a ausência do conteúdo da Cognição Numérica nos cursos de formação para docentes, indica a necessidade de se repensar a formação inicial dos professores, sugerindo a inclusão deste na grade curricular dos cursos de formação, sobretudo no curso de Pedagogia, o qual forma professores que ensinam os diversos conteúdos na Educação Infantil e anos iniciais do Ensino Fundamental.

Por meio desta pesquisa, buscou-se a proposição de caminhos que contribuam para o ensino da Matemática, especialmente para melhorar a qualidade da Educação Infantil, que consiste na primeira etapa da Educação Básica. Ao professor, almejou-se contribuir significativamente em sua prática, sua formação, aproximando-o da pesquisa acadêmica e valorizando seus saberes experienciais. Destaca-se, ainda, a necessidade de maiores estudos sobre a cognição numérica principalmente por parte dos professores, para favorecer o desenvolvimento de habilidades matemáticas e até mesmo, contribuir para que a aprendizagem se torne mais prazerosa e efetiva, e as dificuldades na aprendizagem desse conteúdo sejam diminuídas. 
ELABORATION AND IMPLEMENTATION OF EDUCATIONAL TECHNICAL PRODUCTION: A PRACTICAL AND VISUAL GUIDE FOR MATHEMATICS TEACHING IN EARLY CHILDHOOD EDUCATION AND THE NUMERICAL COGNITION COMPREHENSION

\begin{abstract}
Mathematical knowledge has been present in the child's life since birth, which makes numbers involvement somewhat natural; however, many children manifest anxiety about mathematics and Brazilian assessments have shown unsatisfactory results in the learning of this discipline. The Illustrated Handbook: "A Practical and Visual Guide for Teaching Mathematics in Early Childhood Education and the Numerical Cognition Comprehension" proposes ways that contribute to the teaching of Mathematics in Early Childhood Education, given the scarcity of materials produced in this area. Thus, the general objective of this article is to describe the elaboration and implementation of the activities contained in the aforementioned technical production, discussing the applicability of its activities and analyzing the perception of Infant Education teachers, as to the teaching practice contribution and their Numerical Cognition knowledge. The research results reveal a positive analysis of the developed work, noting that the Illustrated Handbook is applicable to the Early Childhood Education, and relevant to the CMEIS reality. This shows that the Handbook consists in a facilitating and fortifier learning material, as well as into teacher formation. The work emphasizes, to teachers that teach Mathematics in Early Childhood Education, the importance of numerical cognition comprehension, so that it has subventions for its practice and a quality intervention.
\end{abstract}

KEYWORDS: Technical educational production. Numerical Cognition. Mathematics Teaching. Teacher formation. 
10 presente artigo é decorrente de resultados parciais do trabalho de conclusão do Mestrado Profissional em Ensino do primeiro autor, sob orientação da segunda autora. A dissertação, na íntegra, está disponível em https://uenp.edu.br/mestrado-ensino-dissertacoes/ppgen-dissertacoesturma1/10634-sidney-lopes-sanchez-junior/file e o produto educacional em https://educapes.capes.gov.br/handle/capes/204662.

2 A música, neste trabalho, tem como função deixar a atividade mais lúdica e prazerosa, além de compreender um eixo curricular proposto nos Referenciais Curriculares para Educação Infantil (RCNEI) (BRASIL, 1998). Há pesquisas que trazem evidências da utilização da música para o desenvolvimento das habilidades da Cognição Numérica, como por exemplo Arias-Rodrigues (2015), Ribeiro (2013) e Silva (2016).

3 Fonte da música os numerais: https://youtu.be/Zi-cEMm3m9g.

\section{REFERÊNCIAS}

ABUCHAIM, B. de O. Currículo, planejamento pedagógico e cotidiano na préescola: do prescrito-planejamento ao experienciado-vivido. Pontifícia Universidade Católica de São Paulo - PUC (Doutorado em Educação: Currículo), 320 f. São Paulo, 2012.

ARAÚJO, E. A. de; PEREIRA, Z. F.; DANTAS, N. M. R. Entrelaços da formação docente: vivenciando o cotidiano escolar através do PIBID. In: SARMENTOPANTOJA, A., LOBATO, V. da S. M. Dossiê Formação Docente. Revista Interdisciplinar da Divisão de Pesquisa e Pós-Graduação Campus Universitário de Abaetetuba/Baixo Tocantins Universidade Federal do Pará. Versão Digital ISSN:1982-5374 Vol. 10. n. 14 Jun. 2016.

ARIAS-RODRIGUEZ, I. Treino musical como proposta para a estimulação da cognição numérica em crianças de idade escolar. 2015. 115 f. Dissertação de mestrado (Mestre em Psicologia do Desenvolvimento e Aprendizagem) - UNESP, Faculdade de Ciências, Bauru, 2015.

BARBOSA, M. C. S., HORN, M. da G. S., Projetos Pedagógicos na Educação Infantil. Ed. Penso, 2008.

BRASIL. Ministério da Educação e do Desporto. Secretaria de Educação Fundamental. Referencial curricular nacional para a educação infantil / Ministério da Educação e do Desporto, Secretaria de Educação Fundamental. Brasília: MEC/SEF, 1998. 
BRASIL. Ministério da Educação. Coordenação de Aperfeiçoamento de Pessoal de Nivel Superior Diretoria de Avaliação (CAPES). Documento de Área Ensino. 2016.

BRASIL. Lei n. 11.274/2006. Altera a redação dos arts. 29, 30, 32 e 87 da Lei no 9.394, de 20 de dezembro de 1996, que estabelece as diretrizes e bases da educação nacional, dispondo sobre a duração de 9 (nove) anos para o ensino fundamental, com matrícula obrigatória a partir dos 6 (seis) anos de idade. Disponível em: <http://www.planalto.gov.br/ccivil 03/ Ato20042006/2006/Lei/L11274.htm>. Acesso em: 10 mai. 2017.

CIASCA, S. M. Distúrbios de aprendizagem: Uma questão de nomenclatura. Revista Simpro. p. 4-8. 2004.

COLE. L; COLE, S. R. O Desenvolvimento da Criança e do Adolescente. 4a ed. Porto Alegre, 2003.

CARMO, J. do S. SIMIONATO, A. M. Reversão da Ansiedade à Matemática: alguns dados da literatura. Psicologia em Estudo. Maringá, v. 17, n. 2, p. 317-327, abr./jun., 2012.

CORSO, L. V.; Dificuldades na Leitura e na Matemática: um estudo dos processos cognitivos em alunos da 3a a 6ạ série do Ensino Fundamental. 2008. 218 f. Tese (Doutorado em Educação) - Universidade Federal do Rio Grande do Sul. Faculdade de Educação. Porto Alegre, 2008.

CORSO, L. V.; DORNELES, B. V. Senso Numérico e Dificuldades de Aprendizagem na Matemática. Revista de Psicopedagogia, Rio Grande do Sul, v. 27, n. 33, p.298-309, jan. 2010.

COSENZA, R. M. GUERRA, L. B; Neurociência e Educação. Como o cérebro aprende. Artimed. Porto Alegre, 2011.

DEHAENE, S. Varieties of numerical abilities. Elsevier Science Publishers B.v. All Rigths Reserved, Paris, v. 1, n. 44, p.1-42, jan. 1992.

DEHAENE, S. Number Sense. How the mind Creates Mathematics. Oxford. New York. Oxford University Press. 1997.

DEHAENE, S. NACCACHE, L. Towards a cognitive neurocience of consciousness: basic evidence and a workspace framework. Elsevier. Cognition, p. 1-37, 2001. 
GUIMARÃES. V. S. Os saberes dos professores - ponto de partida para formação contínua. In: Formação contínua de professores. Boletim 13, Ministério da Educação, 2005.

GEARY, D. C. Fom infancy to adulthood: the development of numerical abilities. Europe Child \& Adolescent Psychiatry, Columbia, v. 1, n. 9, p.11-16, jan. 2000.

GELMAN, R.; GALLISTEL, C. R. The child's understanding of number. Cambridge. 1978. $260 \mathrm{p}$.

HAASE, V.G., et al. Contribuitions from specific and general factors to unique déficits: two cases of mathematics learning difficults. Frontiers in Psychology. v. 5, p. 1-17, 2014.

HAUSER, M.; SPELKE, E. Evolutionary and developmental fundations of human knowledge In:GAZZANICA, M. The Cognitive Neuroscience, III. MIT Press, Cambridge, 2004.

LORENA, A. B. de; CASTRO-CONEGUIM, J. de F.; CARMO, J. dos S. Habilidades numéricas básicas: Algumas contribuições da análise do comportamento. Estudos de Psicologia, São Carlos: v. 3, n. 18, p.439-446, jul. 2013.

LORENZATO, S. Educação infantil e percepções matemática. Campinas, SP: Autores Associados, 2006. 197 p.

MACEDO, L.; PETTY, A. L. S.; PASSOS, N. C. Os jogos e o lúdico na aprendizagem escolar. Porto Alegre: Artmed, 2005. 110p.

MARCILESE, M. Aquisição da linguagem e habilidades cognitivas superiores: o papel da língua no desenvolvimento da cognição numérica. Alfa, São Paulo, v. 56, n. 2, p.557-581, jan. 2012.

MCCLOSKEY. M., CARAMAZZA, A., BASILI, A. Cognitive Mechanism in Number Processing and Calculation: Evidence from Dyscalculia. Brain and Cognition, v. 4, p. $171-196,1985$.

MEDEIROS, C. G., RODRIGUES, H. C. C., A Educação Infantil e o ranço do assistencialismo. Cadernos da Escola de Direito e Relações Internacionais, Curitiba, v. 20, p. 7-30, 2014. 
MOLINA, J. et al. Cognição numérica de crianças pré-escolares brasileiras pela ZAREKI-K. Temas em Psicologia, Bauru, v. 23, n. 1, p.123-135, 2015.

MORAES, R. Uma tempestade de luz: A compreensão possibilitada pela análise textual discursiva. Ciência e Educação. v. 9, n. 2, p. 191 - 211. 2003.

MORAES, R. GALIAZZI. M. do C. Análise Textual Discursiva. ljuí: Editora: Unijuí, 2014.

MOREIRA, M. A. Teorias de Aprendizagem. Ed. Pedagógica e Universitária Ltda. São Paulo, 1999.

NACARATO, A. M. PAIVA, M. A. V. A formação do professor que ensina Matemática: perspectivas e pesquisas. Belo Horizonte. Autentica. 2008.

PARANÁ. Secretaria Municipal da Educação. Plano Anual do Berçário ao Pré. Município do norte do Estado do Paraná, 2015.

PISA, OECD. Programme for international student assessment (PISA) Results From Pisa 2015. 2016. Disponível em: <http://www.oecd.org/pisa/PISA-2015Brazil-PRT.pdf> Acesso em: 09 mar. 2017.

PRADO, J. G. M. B. do; FERREIRA, A. T. B. Formação de professores: entre saberes e práticas - um estudo de caso. In: SARMENTO-PANTOJA, A., LOBATO, V. da S. M. Dossiê Formação Docente. Revista Interdisciplinar da Divisão de Pesquisa e PósGraduação Campus Universitário de Abaetetuba/Baixo Tocantins Universidade Federal do Pará. Versão Digital - ISSN:1982-5374 v. 10. n. 14 Jun. 2016.

RIBEIRO, F. S. O efeito do treino musical sobre a capacidade da memória operacional e da cognição numérica de crianças com discalculia do desenvolvimento. 2013. 142 f. Dissertação (Mestrado em Psicologia do Desenvolvimento e Aprendizagem) Universidade Estadual Paulista "Júlio de Mesquita Filho" - Bauru, SP. 2013.

ROTTA, N. T. Transtorno de déficit de atenção/ hiperatividade: aspectos clínicos. In: ROTTA, N. T., OHLWEILER, L., RIESGO, R. dos S. Transtornos da Aprendizagem: abordagem neurobiológica e multidisciplinar. $2^{\circ}$ ed. Artmed. Porto Alegre, 2016.

SANTOS, F. H. dos, et al. Cognição Numérica: Contribuições à Pesquisa Clínica. In: PRADO, P. S. T. do, CARMO, J. dos S. (Org.). Diálogos sobre ensino-aprendizagem da matemática. Abordagens pedagógica e neuropsicológica. São Paulo. Cultura Acadêmica. p.63-91. 2016. 
SANCHEZ JUNIOR, S. L.; BLANCO, M. B., COELHOR NETO, J. Uma revisão sistemática sobre o Ensino da Matemática na Educação Infantil. Revista de Educação, Ciências e Matemática, 2017.

SANCHEZ JUNIOR, S. L. O ensino da Matemática na Educação Infantil e o desenvolvimento da Cognição Numérica. (Dissertação de Mestrado) Programa de Pós Graduação Profissional em Ensino. 2018, 153 f. Disponível em: $<$ https://uenp.edu.br/mestrado-ensino-dissertacoes/ppgen-dissertacoesturma1/10634-sidney-lopes-sanchez-junior/file>

SANCHEZ JUNIOR, S. L.; BLANCO, M. B. Manual Ilustrado: Guia Prático e visual para o ensino da Matemática à partir da compreensão da Cognição Numérica. 2018. Disponível em: <http://educapes.capes.gov.br/handle/capes/204662>

SCHMITHORST, V. J.; BROWN, R. D. Empirical validation of the triple-code model of numerical processing for complex math operations using functional MRI and group Independent Component Analysis of the mental addition and substraction of fractions. Neuroimage, Cincinnati, v. 1, n. 22, p.1414-1420, maio, 2004.

SILVA, P. A.; RIBEIRO, F. S.; SANTOS, F. H. dos. Cognição numérica em crianças com transtornos específicos de aprendizagem. Temas em Psicologia, Bauru, $v$. 23, n. 1, p.197-210, 2015.

SILVA, E. R. DA. Os Efeitos do treino musical sobre a cognição numérica e a memória operacional: um estudo prospectivo em crianças pré - escolares. 2016. 143. f. Dissertação (Mestrado em Psicologia do Desenvolvimento e Aprendizagem) Universidade Estadual Paulista "Júlio de Mesquita Filho", Bauru SP. 2016.

VON ASTER. M. G.; SHALEV, R. S. Number development and developmental dyscalculia. Developmental Medicine \& Child Neurology, Berlin, Germany, n. 49, p.868-873, jan. 2007. 
Recebido: 11 jul. 2018

Aprovado: 16 set. 2020

DOI: $10.3895 /$ rbect.v13n3.8548

Como citar: JÚNIOR, S. L. S.; BLANCO, M. B. Elaboração e implementação da produção técnica educacional: um guia prático e visual para "O ensino da matemática na educação infantil à partir da compreensão da cognição numérica". Revista Brasileira de Ensino de Ciência e Tecnologia, Ponta Grossa, v.13, n. 3, p. 20-49, set./dez. 2020. Disponível em:

<https://periodicos.utfpr.edu.br/rbect/article/view/8548>. Acesso em: XXX

Correspondência: Marília Bazan Blanco - mariliabazan@uenp.edu.br

Direito autoral: Este artigo está licenciado sob os termos da Licença Creative Commons-Atribuição 4.0 Internacional.

\section{(c) (1)}

